\title{
VISITA MUSICAL COMO UMA TECNOLOGIA LEVE DE CUIDADO ${ }^{1}$
}

\author{
Leila Brito Bergold², Neide Aparecida Titonelli Alvim ${ }^{3}$
}

\footnotetext{
${ }^{1}$ Texto elaborado a partir da dissertação "A visita musical como estratégia terapêutica no contexto hospitalar e seus nexos com a enfermagem fundamental”. Programa de Pós-Graduação da Escola de Enfermagem Anna Nery (EEAN) da Universidade Federal do Rio de Janeiro (UFRJ), 2005.

${ }^{2}$ Doutoranda em Enfermagem pelo Programa de Pós-Graduação da EEAN/UFRJ. Chefe do Setor de Musicoterapia do Hospital Central do Exército. Rio de Janeiro, Brasil. E-mail: leilabergold@terra.com.br.

${ }^{3}$ Doutora em Enfermagem. Professor Associado do Departamento de Enfermagem Fundamental da EEAN/UFRJ. Orientadora da dissertação. Rio de Janeiro, Brasil. E-mail: titonelli@terra.com.br.
}

RESUMO: Esse estudo teve por objetivo descrever as concepções de clientes hospitalizados sobre as visitas musicais e analisar a importância dessas visitas no contexto hospitalar. Utilizou como bases teóricas a teoria humanística do cuidado de enfermagem de Jean Watson e as contribuições de Even Ruud sobre música e contexto cultural. O estudo foi realizado com abordagem qualitativa, e para produção de dados utilizou o Método Criativo e Sensível através de três dinâmicas denominadas Corpo-Musical. Os sujeitos foram 14 clientes internados em um hospital militar da cidade do Rio de Janeiro. A análise dos dados foi baseada na análise de discurso. Os resultados indicam que as visitas musicais promovem conforto, bem-estar, expressão de emoções, autonomia e estimulam a criação de recursos próprios aos clientes hospitalizados. Estes também apontam a influência benéfica das visitas para o ambiente hospitalar ao promover a comunicação e integração dos seus participantes.

DESCRITORES: Enfermagem. Musicoterapia. Tecnologia.

\section{MUSIC VISITATION AS A LIGHT TECHNOLOGY OF CARE}

\begin{abstract}
This study had as purpose to describe hospitalized client's conceptions on musical visitations and to analyze the importance of these visitations in the hospital context. The theoretical basis used on this study was Jean Watson's humanistic theory of nursing care and the contributions of Even Ruud related music and cultural context. A qualitative approach was used, and Sensitive-Creative Methodology was used for the data production through three dynamics called Body-Musical. The subjects were 14 clients admitted at a military hospital in Rio de Janeiro, Brazil. Data were analyzed by discourse analysis. The results indicate that musical visitations promote comfort, well-being, expression of emotions, autonomy and stimulate the creation of self resources for the hospitalizated clients. These also point the positive influence of visits to promote communication and the integration of participants at the hospital environment.
\end{abstract}

DESCRIPTORS: Nursing. Music therapy. Technology.

\section{LA VISITA MUSICAL COMO UNA TECNOLOGÍA LEVE DEL CUIDADO}

RESUMEN: Este estudio tuvo el objetivo de describir las concepciones de los pacientes hospitalizados acerca de las visitas musicales y analizar la importancia de esas visitas en el contexto hospitalario. La base teórica utilizada en este estudio fue la teoría humanística del cuidado de enfermería de Jean Watson y las contribuciones de Even Ruud acerca de la música y del contexto cultural. Los datos de la investigación fueron producidos por medio del método creativo-sensible a través de tres dinámicas denominadas cuerpo musical. Los sujetos fueron 14 pacientes internados en un hospital militar de la ciudad de Rio de Janeiro. Para el análisis de los datos fue utilizado el análisis del discurso. Los resultados indican que las visitas musicales producen confort, bienestar, expresión de las emociones, autonomía y estimulan la creación de recursos propios a los pacientes hospitalizados. Los sujetos también señalan el beneficio de las visitas para el ambiente hospitalario al promover la comunicación e integración de los participantes

DESCRIPTORES: Enfermería. Musicoterapia. Tecnología. 


\section{INTRODUÇÃO}

Tecnologia é um conjunto de conhecimentos, especialmente princípios científicos que se aplicam a determinado ramo de atividade. Não está ligada somente a equipamentos tecnológicos, mas também ao saber-fazer. ${ }^{1}$ Nessa perspectiva, este estudo abordou uma tecnologia em saúde denominada visita musical, que consiste em apresentações musicais ao vivo em enfermarias de um hospital geral, realizadas por uma equipe de funcionários que cantam e tocam música, coordenados por uma enfermeira que também é musicoterapeuta. Tem por objetivo promover a humanização hospitalar junto a clientes internados, reduzindo assim, as possíveis repercussões negativas da hospitalização relacionadas ao afastamento de seu cotidiano e inserção em um ambiente desconhecido que se torna frequentemente ameaçador. ${ }^{2}$

Dessa forma, é importante que novas tecnologias sejam desenvolvidas para sustentar uma assistência à saúde mais humanizada no ambiente hospitalar. Com esse intuito, foi realizado um estudo junto a clientes internados que participaram das visitas musicais, buscando aprofundar o conhecimento sobre sua influência no contexto hospitalar e refletir sobre os princípios que as fundamentam.

As tecnologias envolvidas no trabalho em saúde são classificadas como: dura, leve-dura e leve. As duras são relacionadas aos equipamentos tecnológicos, normas, rotinas e estruturas organizacionais. As leve-duras são os saberes bem estruturados no processo de saúde e as tecnologias leves estão vinculadas à produção de relações, de vínculos, autonomização e acolhimento. ${ }^{3}$ Assim, pode-se considerar a visita musical uma tecnologia leve, pois os resultados da pesquisa apontaram que ela se vincula ao estabelecimento de relações e autonomização. Observa-se também uma estreita relação entre a visita musical e os pressupostos de teóricas da enfermagem sobre o cuidado, visto que produzir relações e estabelecer vínculos é condição fundamental no cuidado. ${ }^{1}$

A utilização da música como um recurso para o cuidado de enfermagem em nosso país tem ocorrido de forma mais estruturada recentemente. No entanto, como possibilidade terapêutica, a música já é cogitada desde o início da organização da enfermagem como profissão, quando Nightingale se referiu aos seus benefícios. Apesar de não explicitar esses efeitos, ela citava a voz, os instrumentos de sopro e de cordas como benéficos pelo seu som contínuo. Essas afirmações apontam uma percep- ção das possibilidades da utilização terapêutica da música no hospital, à sua época. Contudo, ela concluiu que o seu uso generalizado estaria fora de questão devido ao alto custo financeiro que isso acarretaria. ${ }^{4}$

Atualmente, o desenvolvimento tecnológico facilita o acesso à música, possibilitando a sua presença no ambiente hospitalar. Entretanto, o que mais parece contribuir para a sua utilização hoje é a evolução da concepção do cuidar em enfermagem. Os questionamentos, ora feitos pelos profissionais de enfermagem acerca de sua práxis prioritariamente sustentada em tecnologias duras e leve-duras, resultaram na ampliação de suas possibilidades de atuação, aproximando-os mais do cuidado humanizado.

A mudança de paradigma da Enfermagem para além da pós-modernidade se estrutura sobre o cuidar baseada em uma ontologia, uma ética de relacionamento, de ligação e consciência. Essa consciência está relacionada à mudança de visão de si e do outro, em uma procura de mudança ontológica no modelo de cuidar. ${ }^{5}$

A Enfermagem, ao mudar seus parâmetros acerca do cuidado, procura atender o homem em sua integralidade, e para isso, busca em outras disciplinas recursos que possam ampliar sua prática. Uma dessas disciplinas com as quais a Enfermagem encontra afinidade é a musicoterapia, pois esta também busca uma visão holística do homem para atendê-lo de forma abrangente. Cabe ressaltar que a própria musicoterapia é híbrida, pois se baseia tanto na arte, por meio da música, quanto na ciência, com os fundamentos terapêuticos da utilização desta. ${ }^{6}$

$\mathrm{Na}$ atualidade, com a mudança da concepção do que é o cuidado de enfermagem, alguns enfermeiros brasileiros desenvolveram atividades musicais na prática ou investigaram a utilização da música como um recurso para a assistência dentro de uma visão holística do ser humano. Há publicações que relatam experiências práticas ou descrevem relatos de pesquisas voltadas para: reduzir a dor crônica; promover a interação enfermeira-cliente ou da própria equipe; promover o bem-estar ou prevenir o estresse no ambiente hospitalar; servir como facilitadora no processo de ensino-aprendizagem voltado tanto para clientes quanto para enfermeiros..$^{7-13}$

Uma das pesquisas que abordaram a música como recurso para o tratamento da dor crônica apontou que as músicas lentas e suaves, no caso, do estilo New Age, reduzem mais a dor do que as 
de ritmo acentuado; ${ }^{7}$ enquanto outra apontou uma relação entre a redução da dor e imagens mentais decorrentes de músicas clássicas, em especial as músicas com estruturas bem definidas. ${ }^{8}$

Alguns outros estudos focaram a música como facilitadora de relacionamentos, tanto na relação enfermeiro-cliente quanto na equipe de enfermagem entre si. No primeiro estudo, os sujeitos eram clientes em tratamento psiquiátrico que passaram por um relaxamento induzido por música clássica e que relataram experimentar sensação de bem-estar, prazer e liberdade além de recordaremse de fases da vida e do cotidiano. ${ }^{9} \mathrm{O}$ segundo estudo baseou-se na prática do canto coral para promover a integração da equipe e apontou que essa atividade, além de integrar a equipe de enfermagem e multiprofissional, desenvolveu o espírito de ajuda e a percepção da importância do trabalho em equipe como um todo indivisível. ${ }^{10}$

Outro estudo se originou de uma investigação sobre a música como instrumento para influenciar as relações de trabalho entre a equipe multidisciplinar dentro de uma Unidade de Terapia Intensiva. Essa proposta se estendeu para os clientes com a finalidade de diminuir o estresse, tendo êxito no sentido de proporcionar relaxamento e conforto espiritual a estes. Quanto à equipe, além de auxiliar na prevenção do desgaste psicológico, a música promoveu um maior comprometimento com as atividades profissionais e estimulou a integração social. ${ }^{11}$

Acerca de seu uso voltado para o processo de ensino e aprendizagem, um estudo abordou o aprendizado de temas relacionados ao autocuidado na gravidez através da criação de paródias. Essa atividade lúdica produziu prazer e proporcionou a expressão dos sentimentos das gestantes, assim como dos conhecimentos adquiridos sobre o período de gestação. ${ }^{12}$ Outro estudo se voltou para a sensibilização de enfermeiros utilizando a música como um recurso terapêutico voltado para a prática e o ensino de enfermagem. Os enfermeiros apontaram que a música influencia o indivíduo de forma global, estando suas reações vinculadas às suas vivências e ao seu contexto cultural. Destacaram também seu potencial para promover o auto-conhecimento, reflexão e percepção do outro, sendo ainda um recurso usado pelos enfermeiros para relaxar, estudar e estimular a criatividade. ${ }^{13}$

É importante destacar que a música envolve reações sensoriais, hormonais, fisiomotoras e psicológicas, não havendo fragmentação entre os seus efeitos, como foi apontado em algumas dessas pesquisas que, ao focalizarem algum efeito específico da música, perceberam que a sua influência era mais abrangente, não podendo ser reduzida a um aspecto somente. Assim, sua utilização terapêutica deve ser vista de forma holística de modo a atender o ser humano como um todo, respeitando o seu potencial e a sua forma de ser. ${ }^{2}$

A despeito dos efeitos benéficos da música já relatados, a necessidade de desenvolver novas formas de abordagem no cuidado, pautadas pela observância dos princípios ético-morais na convivência entre enfermeiros e clientes, implica em investigar amplamente essas novas práticas para ampliar o conhecimento e fornecer parâmetros eficazes para a consolidação dessas experiências. Frente a essas reflexões, buscou-se pesquisar as visitas musicais na ótica do cliente hospitalizado e suas interfaces com a enfermagem fundamental, tendo por objetivos: descrever as concepções de clientes hospitalizados sobre as visitas musicais, analisar a importância dessas visitas como estratégia terapêutica no contexto do cuidado hospitalar e discutir as interfaces das visitas musicais com a enfermagem fundamental.

\section{Princípios que fundamentam a tecnologia visita musical}

As visitas musicais vêm sendo desenvolvidas desde o ano de 2000 no Hospital Central do Exército (HCE), na cidade do Rio de Janeiro. O saber-fazer que as sustentam, fundamenta-se na experiência prática e em princípios da Musicoterapia e da Enfermagem.

O cuidar na atualidade requer uma epistemologia em expansão e integra todas as formas de conhecimento. Essa integração dos conhecimentos aponta a importância da música na saúde, pois esta atua como catalisadora no sentido de facilitar e aumentar nossas próprias capacidades interiores de cura e auto-cura. ${ }^{2}$

Sendo tecnologia uma ação intencional sobre a realidade na busca de bens/ produtos fundamentados em um conjunto de conhecimentos, neste estudo buscou-se evidenciar a visita musical como uma tecnologia leve voltada para a produção de acolhimento, vínculo e autonomização. ${ }^{1}$ Assim, na seqüência, passaremos a descrever os procedimentos e os princípios da enfermagem e musicoterapia que norteiam esta tecnologia.

A equipe musical canta e toca instrumentos como flauta, cavaquinho e violão, sendo que as músicas podem ser somente instrumentais, ou 
cantadas e acompanhadas pelos instrumentos descritos. Nessas visitas, o cliente internado é convidado a escolher as músicas que o agradem, sendo respeitado o seu desejo de escutá-las ou não, de cantar ou tocar junto, de se movimentar, ou seja, de se expressar livremente a partir da audição musical.

As visitas musicais iniciaram-se na Clínica de Reabilitação e em seguida na Clínica Ortopédica do HCE, locais em que os efeitos da hospitalização se faziam mais presentes devido à longa permanência dos clientes nessas clínicas. Posteriormente foram estendidas a outros setores de internação que solicitaram as visitas, como o Centro de Terapia Intensiva (CTI), Unidade Renal, Coronária e enfermarias de clínica médica, e se estruturaram em função dos dias e horários mais adequados aos diversos setores. Assim, além da longa permanência de internação dos clientes, a solicitação dos próprios setores também foi adotada como critério de inclusão na rotina das visitas, visto que cada setor conhece sua demanda que, muitas vezes, não diz respeito somente ao cliente, mas à própria equipe.

Constatamos também a necessidade de que fossem realizadas por mais de um integrante da equipe, para facilitar o transporte e manejo dos instrumentos e pastas criadas como arquivos para oferecer a possibilidade de escolha de diferentes estilos musicais: música popular brasileira, samba, sertanejo, rock, seresta, música gospel e outros.

Um procedimento importante é o cuidado que a equipe tem para evitar propagar infecção hospitalar, havendo encontros para reciclar as informações fornecidas pela Comissão de Infecção Hospitalar. Todo o material necessário é transportado em um carrinho adaptado para esse fim, evitando-se assim utilizar qualquer parte da enfermaria para apoiar pastas ou instrumentos. Há recomendações constantes para a higienização das mãos e materiais.

Quanto à escolha dos participantes, todos os clientes dos setores agendados são visitados, à exceção de quando há um número elevado de clientes hospitalizados. Neste caso, é solicitada à equipe de enfermagem que proceda a indicação destes, considerando como critérios a longa permanência, o isolamento da família e a alteração do humor.

No contexto dessas visitas, empregamos o termo música terapêutica para designar a utilização da música por outros profissionais com uma intenção voltada para relaxar, reduzir o estresse ou manejar a dor, diferenciando do termo musicoterapia que designa uma atividade profissional, desenvolvida por um musicoterapeuta que maneja técnicas terapêuticas específicas. ${ }^{14}$

Quanto aos princípios que norteiam a visita musical, um dos mais importantes é a postura ética que guia o profissional de enfermagem quanto ao respeito à autonomia do cliente no sentido de escolher e participar ativamente de seu cuidado. Um dos pressupostos básicos para a ciência do cuidar em enfermagem, aponta para o ambiente de cuidado como sendo aquele que oferece o desenvolvimento do potencial e permite que a pessoa escolha a melhor ação para si mesma em um determinado momento. ${ }^{15}$ Isso evidencia que a possibilidade de escolha no momento da visita musical faz do cliente co-partícipe do cuidado, o que o auxilia no desenvolvimento do seu potencial.

Outro princípio das visitas musicais se baseia em um dos fundamentos da musicoterapia, qual seja, o de que através da escolha musical, o cliente tem a possibilidade de expressar sua subjetividade, embora essa opção não esteja relacionada somente ao valor estético, e sim às suas preferências influenciadas pela cultura na qual está imerso. ${ }^{16}$

A escolha musical de uma pessoa reflete a sua própria identidade, ou seja, é uma maneira de representar o sentido de si mesma, de sua singularidade, e está relacionada ao fato de a música, estando presente no cotidiano, criar memória de sentimentos ligados aos eventos importantes da vida, dando origem a uma biografia musical vinculada à biografia de cada pessoa. Assim, em qualquer atividade terapêutica que envolva manifestações musicais, é importante respeitar as singulares representações da música e não impor uma nova linguagem ou modelo para o cliente reescrever suas experiências. Agir a partir do repertório musical do cliente é um princípio importante da visita musical, pois está de acordo com o respeito básico à sua identidade musical, à sua dignidade e aos direitos humanos. ${ }^{17}$

Com essa visão, as visitas musicais foram desenvolvidas para reduzir os efeitos negativos da hospitalização, pois o cliente é submetido a regras, normas e rotinas do hospital, o que transforma a sua condição de doente em paciente. Nesse momento, muitas vezes, ele perde a autonomia sobre o seu corpo, passando de sujeito a objeto dos cuidados, situação que pode promover um processo de despersonalização. ${ }^{18}$ Dessa forma, essas visitas promovem a humanização do ambiente hospitalar trazendo ao cliente internado um sentimento de 
familiaridade através das músicas escolhidas por ele, e que fazem parte do seu cotidiano. ${ }^{2}$

Observou-se também, que as visitas musicais promovem um verdadeiro encontro entre clientes, familiares, membros da equipe de enfermagem ou multidisciplinar e os integrantes da equipe musical, pois a música estimula a participação de todos. Enquanto estratégia terapêutica junto ao cliente hospitalizado, as visitas musicais se aproximam do que Watson considera o momento de cuidado, ponto focal no espaço e no tempo que envolve ação e escolha entre os sujeitos do cuidado, criando uma conexão entre ambos. ${ }^{19}$ Este é outro princípio da visita musical, fundamentado na importância da presença e atitude da enfermeira para que se desenvolva esse momento de cuidado.

A arte de cuidar é compartilhada e gera condições de identidade e de parentesco relacional. Ao mesmo tempo, pode produzir rupturas com o rigor e a rigidez da disciplina e lançar clientes e enfermeiros na vivência prazerosa das relações humanas. A arte da enfermagem pode adquirir variedade, som e movimento transformando o sofrimento em riso, graça e leveza, tornando o trabalho mais interessante e prazeroso ${ }^{20}$ sendo este considerado também mais um princípio que fundamenta a tecnologia visita musical, tendo em conta que a equipe deve tentar criar um ambiente lúdico, leve e prazeroso que facilite a comunicação e interação entre os participantes. Nesse contexto, a visita musical pode ser considerada uma tecnologia leve baseada em procedimentos e princípios voltados para o bem estar e a interação de seus participantes.

\section{METODOLOGIA}

Esta pesquisa foi aprovada pelo Comitê de Ética em Pesquisa da Escola de Enfermagem Anna Nery/Hospital Escola São Francisco de Assis, sob o Protocolo $N^{\circ}$ 006/05, tendo sido respeitados os princípios éticos previstos na Resolução Nº 196/96, do Conselho Nacional de Saúde.

A necessidade de aprofundar aspectos relacionados à subjetividade dos sujeitos da pesquisa direcionou a escolha metodológica para um estudo do tipo qualitativo e pela utilização do Método Criativo e Sensível (MCS), que valoriza a criatividade e a sensibilidade na produção dos dados evitando a dicotomia entre razão e emoção. ${ }^{21}$

O MCS valoriza a dimensão social e coletiva do conhecimento assim como a linguagem artística e a sensibilidade, aspectos constitutivos das Dinâmicas de Criatividade e Sensibilidade
(DCS) que são a base desse método. Nessas dinâmicas foram empregados materiais e atividades que estimularam a criatividade dos participantes através da arte, levando-os, pela discussão grupal, à reflexão crítica de sua realidade. A DCS Corpo-Musical utilizada nessa pesquisa focalizou a influência da música no corpo para auxiliar a expressão da subjetividade dos participantes das visitas musicais. Tendo-se a perspectiva de que existência e corpo formam uma só realidade, o objetivo principal dessa dinâmica foi resgatar as experiências vivenciadas pelos participantes no ambiente hospitalar, relacionadas à lembrança de seu contexto histórico, cultural e social estimulada pelas visitas musicais.

A pesquisa teve como cenário o local onde se desenvolvem as visitas musicais, o HCE. A unidade de internação escolhida para a pesquisa foi a Clínica Ortopédica, por manter períodos mais longos de internação, em torno de um a seis meses, pela característica do próprio tratamento.

Para a produção dos dados, foram desenvolvidas três dinâmicas iguais, denominadas Corpo-Musical, no período de março a maio de 2005. Cada dinâmica contou com a participação de quatro a cinco clientes, totalizando 14 sujeitos com idades entre 19 a 45 anos, dos 50 clientes internados à época na Clínica Ortopédica. Houve participação de apenas uma mulher entre os sujeitos, pois a maioria dos clientes nesta clínica eram homens que sofreram acidentes relacionados ao trabalho ou ao lazer. Foram identificados com cognomes próprios, escolhidos por cada um deles. Os critérios de inclusão foram: participação em ao menos uma visita musical não havendo limite de participações, aquiescência em colaborar com a pesquisa, além de apresentarem condições mentais e físicas adequadas para poderem se expressar com clareza e se deslocarem até o local da pesquisa. $\mathrm{O}$ intervalo entre as participações dos sujeitos nas visitas musicais e a produção dos dados para a pesquisa, através do desenvolvimento da dinâmica Corpo-Musical foi de no mínimo um dia e no máximo 10 dias.

As três dinâmicas realizadas seguiram cinco etapas, iniciando com a apresentação dos clientes participantes e da equipe de pesquisa, composta pelo coordenador, observador e apoiador logístico. Nessa etapa foram também explicados coletivamente os objetivos da pesquisa e os procedimentos que seriam realizados no decorrer da dinâmica, sendo em seguida apresentado e assinado o Termo de Consentimento Livre e Esclarecido. Na segun- 
da etapa, houve o enunciado da temática a visita musical sendo solicitado aos participantes que se concentrassem nela, e, em seguida, o relaxamento induzido por uma música clássica denominada Cânon de Pachelbel, de andamento lento e com duração de três minutos, adequada ao objetivo de focalizar a atenção no tema proposto. ${ }^{13} \mathrm{Na}$ terceira etapa foram enunciadas as questões geradoras de debate - Que efeitos a visita musical causou no seu corpo? Como vocês se sentiram? Em seguida, foi solicitado que os participantes escrevessem em papéis adesivos o que haviam sentido durante as visitas musicais. Estes deveriam ser colados pelos sujeitos em alguma parte da silhueta de um corpo desenhada em cartolina e que havia sido colocada sobre uma mesa no meio de um círculo no qual eles estavam sentados. Na quarta etapa cada participante produziu somente um papel adesivo no qual codificou a sua percepção da visita musical e escolheu um local no corpo para colá-lo, apesar do esclarecimento de que poderiam utilizar mais de um papel e colar em outras partes da silhueta desenhada. Logo a seguir, na última etapa, os sujeitos apresentaram sua produção individual, no processo de descodificação que promoveu a discussão crítica-reflexiva que veio a seguir, muito intensa devido ao envolvimento emocional dos participantes. Ao final da discussão foi realizada a recodificação, quando os sujeitos refletiram sobre as questões surgidas na dinâmica, validando os temas desenvolvidos pelos participantes. ${ }^{21}$

A produção dos dados foi gravada em fita magnética e transcrita em seguida. Para análise dos dados foram utilizadas algumas ferramentas da análise de discurso: o dito e o não dito; o interdiscurso; os processos parafrásticos e as metáforas. $^{22}$

\section{RESULTADOS E DISCUSSÃO}

\section{Influências das visitas musicais sobre o clien- te hospitalizado}

Os sujeitos da pesquisa durante a dinâmica Corpo-Musical apontaram as diferentes influências da visita musical sobre os seus corpos, escrevendoas nos papéis colados na silhueta desenhada previamente. Apontaram predominantemente as regiões da cabeça e do peito, e um participante apontou a região do umbigo, explicando em seguida, que havia situado o centro do corpo para destacar a influência sobre todo o corpo.

A cabeça foi apontada como a região do corpo que mais sofreu influência das visitas musicais, o que está em consonância com outra pesquisa que utilizou a dinâmica Corpo-Musical na produção de dados. Nela, os sujeitos também apontaram uma influência maior na cabeça por ser a parte do corpo que capta e percebe primeiro a música. As diferentes percepções da música podem ser relacionadas ao fato de que esta influencia cada pessoa de forma singular devido às suas implicações individuais, havendo diferenças na percepção e sentimentos de cada um. ${ }^{13}$

Um dos participantes se referiu à propriedade da música em despertar lembranças relacionadas a vivências pessoais, que fazem parte da biografia musical de cada um. ${ }^{17}$ A música, ela efetua a cabeça, porque nela faz lembrar dos nossos passados em matéria de amor antigo, que você já passou (Renato).

Para outro, ela desloca o foco da atenção dos problemas relacionados à internação ou à própria doença, inserindo os sujeitos em uma perspectiva de saúde: senti um grande alívio, como se todos os meus problemas tivessem acabado. Como se tudo estivesse ótimo; como se existisse só eu no local (Leandro).

O música promove relaxamento, o que foi constatado no âmbito das visitas por um dos sujeitos, ratificando o resultado de outras pesquisas. ${ }^{8,11,13}$ Foi uma forma relaxante, em que a mente esvazia todas as tensões exercidas sobre ela, em que o corpo se moderniza em pensamentos melhores (Ricardo).

A relação feita por este sujeito entre o relaxamento e os pensamentos melhores aponta uma outra influência da visita musical, o estímulo à reflexão, o que foi corroborado por outro participante: boa prá cabeça, prá parar e pensar mais (Jader).

Nas discussões grupais, os participantes apontaram que a alteração do foco perceptual no âmbito das visitas musicais não era somente um mecanismo de esquecimento ou fuga, mas um momento de contato do cliente com sua subjetividade e/ou um momento de reflexão sobre os acontecimentos que influenciavam sua vida naquele momento. As canções que sublinham e destacam as vivências estão carregadas de características subjetivas, ou seja, de seus sentidos. Assim, a própria canção permite compreender as emoções provenientes das vivências, sendo possível por meio delas experimentar informações acerca da realidade vivida. ${ }^{2}$

Outro participante apontou um aspecto importante relacionado às visitas musicais: o aumento da auto-estima. A atenção dispensada aos clientes internados durante a visita aumenta a auto-estima que fica abalada quando ocorre um período longo de internação em que as visitas dos 
amigos ou familiares começam a escassear, como ocorreu com o sujeito que escreveu: me senti lembrado, ou seja, uma pessoa muito importante; melhorou bastante a minha cabeça (Joaquim).

Outro participante apontou o prazer que obteve ao participar das visitas musicais: alegria. Felicidade (Vilmar).

Essa constatação também foi feita por outro sujeito que, além disso, apontou outros sentimentos que se modificavam na presença da visita, conforme explicou no momento da discussão grupal: alegria. O tempo passava mais rápido. Saudades. Solidão (Charles).

O prazer proporcionado pela música exige que o ouvinte participe, gerando um fluxo de antecipações musicais, ou seja, exige uma participação ativa, e não passiva da audição musical. Mas a emoção positiva só surge se a música ouvida corresponder ao universo sonoro e/ou aos padrões estéticos do ouvinte, porque apenas desse modo é possível fazer a antecipação do movimento musical esperado, obtendo-se assim prazer com a expectativa confirmada. ${ }^{16}$

Os participantes que indicaram a região do peito no momento da produção artística, expressaram o senso comum de que esta é a parte relacionada ao coração ligado simbolicamente às emoções. Os sujeitos também se referiram ao alívio da tensão, agonia e tristeza, ressaltando que estas se transformaram também em alegria. Contudo, ao se expressarem através da escrita, o fizeram de uma forma muito mais intensa do que os participantes que apontaram a região da cabeça, expressando toda a mobilização emocional promovida pelas visitas musicais.

Pelo motivo de estar internado, a música alivia um pouco a tensão e agonia de estar apenas deitado. A saudade dos meus filhos, e resumindo, a dor no peito de estar enfermo. Te traz mais alegria quando há música na enfermaria (Fernando).

Estava horrivel, triste, chorei. Depois da música, senti uma felicidade e melhorei (Elisa).

Uma grande emoção e alegria. Muito gratificante (Geraldo).

A expressão de sentimentos, positivos ou negativos, é considerada como um fator de cuidado, pois melhora o nível pessoal de percepção além de facilitar a compreensão do comportamento que é gerado a partir desses sentimentos. A expressão destes e a consequente compreensão podem facilitar a comunicação e interação entre o cliente e a enfermagem. ${ }^{19}$
A intensidade com que expressaram seus sentimentos estava também relacionada à lembrança de pessoas muito próximas afetivamente dos sujeitos.

Emoção; lembrança da mãe; vontade de ficar curado do braço (Paulo).

Esta música me fez lembrar da minha avó, que faleceu no ano passado. Minha avó não gostava de nenhum estilo de música, ela só gostava do estilo clássico. Me fez lembrar de tudo o que ela fez por mim (Denis).

Outra questão importante se refere à possibilidade da música de produzir uma sensação de transcendência e de conexão com uma instância superior, ligada ou não a aspectos religiosos. ${ }^{17}$

Algo que nos faz esquecer de tudo. Como fosse lá do fundo da alma (Zito).

Durante as visitas musicais, alguns participantes solicitaram músicas religiosas, e relataram no momento da discussão grupal que estas lhes trouxeram alívio, força e esperança. Outra pesquisa sobre os efeitos da música no processo de humanização em um CTI constatou que a música pode trazer relaxamento e conforto espiritual, sendo um importante subsídio na busca de alternativas que contemplem a pessoa na sua integridade. ${ }^{11}$ A dimensão religiosa inclui experiências em que a vida pode ser percebida como parte de alguma ordem maior, como se o corpo e a mente estivessem cheios de energia e poder, podendo ter um efeito terapêutico em situações em que a pessoa se sente fragilizada. ${ }^{17}$

O sujeito que colou seu adesivo no centro do corpo quis demonstrar que todo o corpo havia sido influenciado pela música, ratificando os resultados de outra pesquisa. ${ }^{13} \mathrm{~A}$ música em si, ela traz um conforto, alegria, harmonia. Enfim, a mim ela traz tranqüilidade para o corpo todo (Marcos).

Relacionamos também as visitas musicais aos elementos promotores de conforto encontradas nos discursos dos sujeitos e apontada por este participante: liberdade, integração, melhora, segurança, cuidado e comodidade. ${ }^{23}$

É importante destacar que a escolha da música pelo cliente nas visitas musicais estimulou a expressão da sua subjetividade, garantindo sua autonomia e sua participação ativa nessa estratégia de cuidado. Para alguns participantes, estimulou ainda a criação de recursos próprios com a finalidade de alterar a sua realidade através da gravação da música tocada na visita e reproduzida posteriormente com o objetivo de diminuir o medo do cliente; da execução nas enfermarias de 
seus próprios instrumentos musicais trazidos de casa, diminuindo a ociosidade; da descoberta do prazer de partilhar o canto ou iniciar/reiniciar o estudo de música com o auxílio dos integrantes da equipe de música.

Dessa forma, a visita musical ampliou o auto-conhecimento, fazendo-os descobrir ou redescobrir o seu próprio potencial. Esses recursos desenvolvidos pelos participantes vêm ao encontro de outro pressuposto básico, que afirma que o cuidado efetivo promove a saúde e o crescimento individual e familiar, demonstrado pela busca de alternativas saudáveis de convivência no ambiente hospitalar. ${ }^{15}$

\section{Influência da visita musical sobre o ambiente do cuidado}

Durante a discussão crítico-reflexiva, no momento da decodificação da produção artística, a maioria dos participantes apontou sofrimentos causados pela hospitalização: solidão, afastamento familiar e suspensão de suas funções sociais. $\mathrm{O}$ hospital é um ambiente promotor de ansiedade pela ruptura do cotidiano do cliente e pela imposição de rotinas estranhas a ele.

Contudo, se por um lado fazemos parte dessa rotina, também podemos desenvolver intervenções terapêuticas no sentido de minimizar esses efeitos negativos da hospitalização. No nascimento da enfermagem moderna, Nightingale defendia a idéia de que o ambiente ideal seria aquele capaz de manter o organismo em condições para não adoecer ou para se recuperar de doenças, destacando também o lado humano da assistência de enfermagem. ${ }^{4}$ Nesse contexto, se a música tocada durante as visitas musicais fizer parte do cotidiano e da biografia musical do cliente, ele pode reconhecer-se nela e estender esse reconhecimento ao ambiente da internação, que poderá assim tornar-se menos ameaçador, promovendo o acolhimento nesse ambiente.

Os participantes também discutiram que as visitas musicais vão além da influência sobre seus corpos. Elas potencializam seus efeitos e ampliam seus objetivos, na medida em que promovem a participação de seus integrantes clientes, familiares, equipe de música e de enfermagem. O espaço das visitas é, portanto, relacional e integrador promovendo mudanças no ambiente hospitalar, tornando-o mais favorável à recuperação do cliente internado.

É importante destacar que a enfermagem não faz apenas parte do ambiente hospitalar. Ela pode ser considerada o próprio ambiente, já que é responsável por grande parte de sua organização. Assim, se a enfermagem é parte do ambiente é necessário que se focalize nele, assumindo que sua atitude pode fazer diferença e buscando alternativas para construir um ambiente mais saudável, promovendo dessa forma a recuperação do cliente. *

Entre as modificações ocorridas no ambiente, os sujeitos apontaram que as visitas musicais favorecem a ludicidade, contribuindo para diminuir a inatividade. A inatividade aliada à rotina hospitalar cria uma sensação de monotonia que agrava a angústia do cliente hospitalizado. Nesse sentido, as próprias atividades concebidas para o lazer, como escutar rádio ou ver televisão, foram consideradas monótonas por alguns participantes por não terem variedade.

É importante proporcionar variedade no ambiente hospitalar, pois a ansiedade é intensificada nas pessoas que não podem variar de atividades. Nightingale apontava a importância da variedade para a mudança do foco do pensamento do cliente, para diminuir seu sofrimento. ${ }^{4}$ Dessa forma, as visitas musicais facilitaram o rompimento da rotina e foram apontadas pelos sujeitos como um momento lúdico que distrai e conduz à sensação de bem-estar, conforto, alívio, alegria e relaxamento. O lúdico no cuidado configura-se como possibilidade restauradora da saúde do cliente, na medida em que facilita a interação, promovendo o processo de socialização e comunicação no ambiente hospitalar. ${ }^{24}$

Outro problema apontado pelos participantes relaciona-se aos conflitos que ocorrem derivados da convivência forçada entre pessoas que não têm nenhum vínculo entre si, necessitando partilhar o ambiente com outros clientes e também com seus acompanhantes. A internação prolongada tende a desenvolver um processo de estresse que acaba afetando a todos, clientes, familiares ou acompanhantes e a equipe de enfermagem. Contudo, os sujeitos também apontaram que as visitas musicais reduziram esse estresse, contagiando o ambiente da enfermaria.

\footnotetext{
* Trecho extraído de anotações da conferência "Cuidar em enfermagem além da pós-modernidade" proferida por Jean Watson no Intercâmbio Internacional: Bases Teórico-Filosóficas da Prática do Cuidar em Enfermagem em novembro de 2003 na cidade do Rio de Janeiro.
} 
As visitas musicais resultaram em uma integração entre os clientes e destes com os profissionais de saúde, pois ao promoverem o momento lúdico de encontro minimizaram conseqüentemente os conflitos. Os participantes destacaram também essas visitas como uma estratégia para reduzir o estresse da equipe de saúde, o que aponta a importância de refletir sobre as diferentes maneiras de as enfermeiras cuidarem de si seja com estratégias musicais ou com outras atividades expressivas que promovam relaxamento e maior percepção de si mesmo e do outro. A dimensão humana do cuidado requer que este também seja voltado para os profissionais como pré-condição para se desenvolver uma atitude de compromisso e cuidado para com os clientes. ${ }^{25}$

Outro fator que ampliava a angústia dos sujeitos da pesquisa relacionava-se à solidão e ao afastamento do convívio familiar, que gerava saudade e preocupação com o bem-estar dos familiares. Contudo, durante a discussão grupal, os participantes falaram que as visitas musicais resultaram em diminuição da solidão ao promoveram a integração no ambiente de internação. É importante destacar que a necessidade de integração foi um tema amplamente discutido, devendo ser considerado na construção de um ambiente de cuidado, pois os sujeitos reivindicaram mais atividades musicais coletivas para minimizar o impacto negativo da internação hospitalar.

\section{CONSIDERAÇÕES FINAIS}

Esse estudo apontou, a partir da ótica de clientes internados, que no contexto hospitalar as visitas musicais se constituíram como uma tecnologia leve, pois promoveram acolhimento e auxiliaram a reduzir a sensação de despersonalização aumentando a auto-estima dos participantes. Ao mesmo tempo, proporcionaram conforto e bemestar e promoveram a produção de relações e vínculos dos clientes entre si e com a equipe de saúde, especialmente, de enfermagem. É importante destacar também a relação entre essas visitas e a autonomização do cliente hospitalizado, estimulada a partir da sua escolha musical no momento das visitas e ampliada pelo desenvolvimento de recursos próprios incentivados pelos vínculos criados a partir das mesmas.

A música promove diversas reações e os seus efeitos não podem ser separados, e sim, vistos de forma global e complexa. Nesse sentido, as visitas musicais produziram relaxamento físico e mental, pois reduziram o stress, a tensão e a ansiedade.
Produziram também efeito estimulante ao promoverem contato com o ambiente, aumentando o nível de energia, estimulando atividade motora e elevando o humor. Assim, as visitas musicais constituíram-se como tecnologia de cuidado, pois promoveram a sensação de integralidade devido a sua natureza holística, através da qual se pode promover a melhora na condição de saúde do cliente internado.

A ruptura com a rotina e a rigidez do ambiente hospitalar aponta essas visitas como um recurso tecnológico que expressa a arte de enfermagem ao unir clientes e equipe de enfermagem na vivência prazerosa das relações humanas, transformando o sofrimento em graça, leveza e prazer. Considera-se assim que as visitas musicais, como uma tecnologia leve, têm interfaces com os cuidados fundamentais de enfermagem ao promoverem conforto e bem-estar aos clientes internados e alterarem positivamente o ambiente hospitalar através do estabelecimento de relações e vínculos voltado para uma concepção humanizada do cuidado de enfermagem.

Destaca-se, entretanto, que os efeitos benéficos das visitas não estão ligados restrita ou propriamente à música em si, mas à possibilidade de encontro que estas proporcionam. Nesse enfoque, ao se planejar a utilização da música como um recurso para humanizar o ambiente hospitalar, mesmo que essa não seja executada ao vivo, mas veiculada através de equipamento de som, devese levar em conta a presença e a participação da equipe de enfermagem, em uma genuína atitude de atenção e cuidado.

É importante discutir que nem todos os profissionais de enfermagem possuem habilidades musicais, e que essa habilidade não faz parte da formação profissional. Contudo, mesmo sem tocar um instrumento musical, é possível cantar ou mesmo utilizar equipamento de som para promover alterações positivas no ambiente hospitalar. No entanto, ao considerar que a música oferece múltiplas possibilidades terapêuticas, deve-se pensar também que sua utilização requer novas pesquisas voltadas para o desenvolvimento de tecnologias que possam ampliar a humanização da assistência em saúde.

\section{REFERÊNCIAS}

1. Silva DC, Alvim NAT, Figueiredo, PA. Tecnologias leves em saúde e sua relação com o cuidado de enfermagem hospitalar. Esc Anna Nery Rev Enferm. 2008 Jun; 12(2):291-8. 
2. Bergold LB. A visita musical como estratégia terapêutica no contexto hospitalar e seus nexos com a enfermagem fundamental [dissertação]. Rio de Janeiro (RJ): Universidade Federal do Rio de Janeiro. Programa de Pós-Graduação da Escola de Enfermagem Anna Nery; 2005.

3. Merhy EE. Em busca do tempo perdido: a micropolítica do trabalho vivo em saúde. In: Merhy EE, Onocko R, organizadores. Práxis em salud un desafio para lo público. São Paulo (SP): Hucitec; 1997. p.71-112.

4. Nightingale F. Notas sobre enfermagem: o que é e o que não é. São Paulo (SP): Cortez; 1989.

5. Watson J. Enfermagem pós-moderna e futura: um novo paradigma da enfermagem. Loures (PT): Lusociência; 2002.

6. Chagas M, Pedro R. Musicoterapia: desafios entre a modernidade e a contemporaneidade. Rio de Janeiro (RJ): Bapera; 2008.

7. Giannotti L, Pizzoli L. Musicoterapia na dor: diferenças entre os estilos jazz e new age. Nursing. 2004 Abr; 71(7):35-40.

8. Leão E, Silva M. Música e dor crônica músculoesquelética: o potencial evocativo de imagens mentais. Rev Latino-am Enfermagem. 2004 Mar-Abr; 12(2):235-41.

9. São Mateus LA. A música facilitando a relação enfermeiro-cliente em sofrimento psíquico [dissertação]. Ribeirão Preto (SP): Universidade de São Paulo. Programa de Pós-Graduação em Enfermagem; 1998.

10. Alves M. A música como prática alternativa na integração da Equipe de Enfermagem. Enferm Atual. 2001 Set-Out; 1(5):35-40.

11. Backes DS, Ddine SC, Oliveira CL, Backes MTS. Música: terapia complementar no processo de humanização de um CTI. Nursing. 2003 Nov; 66(6):35-42.

12. Ravelli AP. Percepções de gestantes sobre a contribuição da música no processo de compreensão da vivência gestacional [dissertação]. Porto Alegre (RS): Universidade Federal do Rio Grande do Sul. Pós-Graduação em Enfermagem; 2004.
13. Bergold LB, Alvim NAT, Cabral IE. O lugar da música no espaço do cuidado terapêutico: sensibilizando enfermeiros com a dinâmica musical. Texto Contexto Enferm. 2006 Abr-Jun; 15(2):262-9.

14. Bruscia K. Definindo Musicoterapia. Rio de Janeiro (RJ): Enelivros; 2000.

15. Talento B. Jean Watson. In: George JB. Teorias de Enfermagem: Os fundamentos à prática profissional. $4^{\text {a }}$ ed. Porto Alegre (RS): Artes Médicas Sul; 2000.

16. Jourdain R. Música, cérebro e êxtase: como a música captura nossa imaginação. Rio de Janeiro (RS): Objetiva; 1997.

17. Ruud E. Music Therapy: Improvisation, Communication and Culture. Barcelona (ES): Publisher; 1998.

18. Waldow VR, Cuidado Humano: o resgate necessário. $2^{\mathrm{a}}$ ed. Porto Alegre (RS): Editora Sagra Luzzatto; 1999.

19. Watson J. Watson's theory of transpersonal caring. In: Walker P, Neuman B, organizadores. Blueprint for use of nursing models: education, research, practice and administration. New York (US): N \& N Press; 1996. p. 141-84.

20. Caccavo PV, Carvalho V. A arte da enfermagem efêmera, graciosa e perene. Rio de Janeiro (RJ): UFRJ, Escola de Enfermagem Anna Nery; 2003.

21. Cabral IE. O método criativo e sensível: alternativa de pesquisa na enfermagem. In: Gauthier JHM, Cabral IE, Santos I, Tavares CMM, organizadores. Pesquisa em enfermagem: novas metodologias aplicadas. Rio de Janeiro (RJ): Guanabara Koogan; 1998. p. 177-203.

22. Orlandi EP, Análise de discurso: princípios e procedimentos. $4^{\mathrm{a}}$ ed. Campinas (SP): Pontes; 2003.

23. Arruda EM, Nunes AM. Conforto em enfermagem: uma análise teórico-conceitual. Texto Contexto Enferm. 1998 Mai-Ago; 7(2):93-110.

24. Beuter M. Expressões lúdicas no cuidado: elementos para pensar/fazer a arte da enfermagem [tese]. Rio de Janeiro (RJ): Universidade Federal do Rio de Janeiro. Programa de Pós-graduação da Escola de Enfermagem Anna Nery; 2004.

25. Silva A. A Dimensão Humana do Cuidado em Enfermagem. Acta Paul Enf. 2000; 13 (Esp1):86-90. 